\title{
Non-utilization Is Not the Best Way to Manage Lowland Meadows in Hulun Buir
}

\section{OPEN ACCESS}

Edited by:

Zhanhuan Shang,

Lanzhou University, China

Reviewed by:

Jian Sun,

Institute of Tibetan Plateau Research

(CAS), China

Yu Liu,

Northwest A\&F University, China Duo Feng Pan,

Heilongjiang Academy of Agricultural

Sciences, China

Hongbin $\mathrm{Ma}$

Ningxia University, China

${ }^{*}$ Correspondence:

Guowen Cui

cgw603@neau.edu.cn

†These authors have contributed

equally to this work

Specialty section:

This article was submitted to Functional Plant Ecology,

a section of the journal

Frontiers in Plant Science

Received: 03 May 2021

Accepted: 25 June 2021

Published: 16 July 2021

Citation:

Ji G, Li B, Yin H, Liu G, Yuan Y and Cui $G$ (2021) Non-utilization Is Not the Best Way to Manage Lowland

Meadows in Hulun Buir.

Front. Plant Sci. 12:704511.

doi: 10.3389/fpls.2021.704511

\author{
Guoxu Ji1,2t, Bing Li1t, Hang Yin', Guofu Liu'1, Yuying Yuan' and Guowen Cui ${ }^{1 *}$ \\ 'Department of Grassland Science, College of Animal Science and Technology, Northeast Agricultural University, Harbin, \\ China, ${ }^{2}$ Institute of Environment and Sustainable Development in Agriculture, Chinese Academy of Agricultural Sciences, \\ Beijing, China
}

Carex meyeriana lowland meadow is an important component of natural grasslands in Hulun Buir. However, in Hulun Buir, fewer studies have been conducted on C. meyeriana lowland meadows than on other grassland types. To determine the most appropriate utilization mode for $C$. meyeriana lowland meadows, an experiment was conducted in Zhalantun city, Hulun Buir. Unused, moderately grazed, heavily grazed and mowed meadow sites were selected as the research objects. The analysis of experimental data from 4 consecutive years showed that relative to the other utilization modes, mowing and moderate grazing significantly increased C. meyeriana biomass. Compared with non-utilization, the other three utilization modes resulted in a higher plant diversity, and the moderately grazed meadow had the highest plant community stability. Moreover, principal component analysis (PCA) showed that among the meadow sites, the mowed meadow had the most stable plant community and soil physicochemical properties. Structural equation modeling (SEM) showed that grazing pressure was less than $0.25 \mathrm{hm}^{2} /$ sheep unit and that plant biomass in C. meyeriana lowland meadow increases with increasing grazing intensity, temperature and precipitation.

Keywords: utilization mode, plant community, soil physicochemical properties, temperature and precipitation, Carex meyeriana

\section{INTRODUCTION}

Vegetation is the most basic component of terrestrial ecosystems and interacts with temperature, precipitation, topography, and other factors to determine the ecosystem type (Ge et al., 2004; Liu and Tian, 2010). Vegetation is also the most easily changed component of ecosystems. Changes in the utilization pattern or intensity of vegetation, such as changes in grazing or mowing practices, can directly affect plant species presence and diversity and thus the stability of an entire grassland ecosystem (Socher et al., 2012; Li et al., 2018b). A series of experimental studies have been carried out to understand how external disturbances affect grassland plant communities and how to protect and utilize grasslands.

Overgrazing is one of the main causes of grassland degradation in China and even worldwide (Wang et al., 2011). The impacts of grazing on grassland have consistently been a focus of research. At present, there are two major hypotheses regarding the impact of grazing on grassland plant diversity: the grazing optimization hypothesis and the intermediate disturbance hypothesis. The latter has been supported by a large number of experiments (Fensham et al., 2014; Beck et al., 2015; 
Qin et al., 2019), although some experiments provide no support, in some cases contradicting this hypothesis (Rutherford and Powrie, 2013; Ren et al., 2018). These differences among experimental results indicate that the effects of grazing on grassland communities are complex and result from the combined actions of multiple factors; a change in any one factor, such as livestock species, grass type, a climatic conditions or a soil physicochemical property, can greatly affect the experimental results (Liu et al., 2015; Chu et al., 2019; Ji et al., 2020). Compared with the effect of grazing, the effect of mowing on grassland is more spatially homogeneous and can directly lead to significant reductions in the height and cover of grassland plant communities as well as a reduction in the accumulation of grassland litter (Kose et al., 2019). Current opinions on the impact of mowing on grassland plant diversity are more consistent and include the view that moderate mowing cannot only help stabilize grassland plant communities but also promote grassland plant compensatory growth (Yang et al., 2012). Experiments conducted by BernhardtRömermann et al. (2011), Socher et al. (2012), and Nakahama et al. (2016) demonstrated that moderate mowing was beneficial for maintaining or increasing the stability of plant community diversity and productivity. In grassland ecosystems, the soil and vegetation interact with each other; changes in plant communities affect the use of soil nutrients and ultimately change the soil chemical properties, and changes in soil chemical properties affect plant communities.

Numerous experiments have shown that grazing (Teague et al., 2011; Zhang et al., 2019), mowing (Vermeire et al., 2020; Wang et al., 2020a), and climate change (Hoffmann et al., 2016; Hu et al., 2018) can directly or indirectly affect soil physicochemical properties. Grazing or mowing increase the soil bulk density (SBD) (though not always significantly) until it reaches a stable level (Okach et al., 2018; Xu et al., 2018; Batista et al., 2019). However, the impact of grazing or mowing on soil chemical properties do not exhibit consistent trends (Luo et al., 2019; Yang et al., 2020). Some scholars have found that grazing or mowing does not significantly change soil chemical properties (Kitchen et al., 2009; Swacha et al., 2018; Nakano et al., 2020). However, many experiments have proven that grazing increases soil organic carbon (Wei et al., 2011) or resulted in soil nutrient loss (Zhan et al., 2020).

Therefore, although many experiments have been carried out to study the effects of various utilization modes on grassland, further research is warranted because of the differing effects of experimental factors, such as treatment methods and grassland types. Moreover, global climate change has become an indisputable fact (Ciais et al., 2014), and the responses of grasslands, which are highly sensitive, to climate change are complex (Polley et al., 2014; Ganjurjav et al., 2016; Salick et al., 2019; Harrison, 2020). Therefore, continued exploration of the most appropriate uses of various grassland types under climate change conditions is necessary. The Hulun Buir grassland, located at the eastern edge of the Eurasian grassland, is an important component of the grasslands in northern China and forms an ecological barrier. Many experiments regarding the utilization status of the Hulun Buir grassland have been carried out, but few have been carried out in Carex meyeriana lowland meadow. C. meyeriana is one of the most important grassland constructive species and a dominant species in the lowland meadows of the Hulun Buir grassland; accordingly, C. meyeriana lowland meadow is one of the most important grassland types in this region. Therefore, it is worth discussing whether the intermediate disturbance hypothesis is supported in the utilization of $C$. meyeriana lowland meadow. In this study, C. meyeriana lowland meadow sites under four grassland utilization modes (non-use, mowing, moderate grazing, and heavy grazing) were selected as the research objects. The species composition, biomass, plant diversity, and soil physicochemical properties of these meadow sites were studied to analyze the difference in the impact of four utilization patterns on C. meyeriana lowland meadows, and to explore the rational utilization of C. meyeriana lowland meadows.

\section{MATERIALS AND METHODS}

\section{Study Site and Experimental Design}

The experimental sites were located in Zhalantun city, Hulun Buir, Inner Mongolia, which is a typical temperate zone characterized by a semi-arid continental monsoon climate. The mean annual temperature is $3.7^{\circ} \mathrm{C}$, and the monthly mean temperature ranges from 23.8 to $-17.1^{\circ} \mathrm{C}$ (January to July). The annual mean precipitation is $565.9 \mathrm{~mm}$, and $77.5 \%$ of the precipitation occurs from June to September (data from Zhalantun Meteorological Station, China Meteorological Data Network, 2015).

The experiment was carried out in 2015-2018. Plant community characteristics and soil physicochemical properties in the C. meyeriana lowland meadow were studied under four utilization modes: no utilization (UN), mowing once a year (MO), moderate grazing (MG), and heavy grazing (HG). The mowing site was mowed once every year in mid-late July (during a sunny and rainless period) to a stubble height of $3 \mathrm{~cm}$. Based on the grass yield of the natural grassland in the study area, the appropriate stocking capacity was approximately $0.4 \mathrm{hm}^{2} /$ sheep unit. Therefore, after calculating the actual stocking capacity of the two grazing sites, we determined the grazing intensity of the two sites: approximately $0.37 \mathrm{hm}^{2} /$ sheep unit for the MG site and approximately $0.25 \mathrm{hm}^{2} /$ sheep unit for the HG site. Healthy sheep of the same variety (Mongolian sheep, one of the major local breeds) and of similar weight and age were selected as grazing livestock. The grazing time was from May to October each year, with no grazing occurring in the sites outside of this time. Both grazing sites were open-grazed, without fencing. During the experimental period, the grazing intensity at each of the two grazed sites remained stable. Each site was divided into three plots of similar vegetation status. The area of each experimental site was at least $1 \times 10^{4} \mathrm{~m}^{2}$.

All four sites were in C. meyeriana lowland meadow, and the soil is meadow soil (Chinese classification), corresponding to Ustolls and Mollisols in the US Soil Taxonomy classification. Before the experiment was conducted, all four sites were stable in their use patterns and did not suffer any human disturbance or 
TABLE 1 | Basic information on the test sites.

\begin{tabular}{|c|c|c|c|c|c|c|c|}
\hline Plot & Longitude & Latitude & Altitude & Grassland type & Grassland type & Soil type & Land use \\
\hline UN & $121^{\circ} 33^{\prime} 42.33^{\prime \prime}$ & $47^{\circ} 35^{\prime} 52.45^{\prime \prime}$ & $678 \mathrm{~m}$ & Lowland meadow & C. meyeriana & Meadow soil & Unused \\
\hline $\mathrm{MO}$ & $121^{\circ} 50^{\prime} 28.59^{\prime \prime}$ & $47^{\circ} 40^{\prime} 05.31^{\prime \prime}$ & $515 \mathrm{~m}$ & Lowland meadow & C. meyeriana & Meadow soil & Mowing once a year \\
\hline$M G$ & $121^{\circ} 35^{\prime} 59.04^{\prime \prime}$ & $47^{\circ} 37^{\prime} 14.50^{\prime \prime}$ & 705 m & Lowland meadow & C. meyeriana & Meadow soil & Moderate grazing \\
\hline$H G$ & $122^{\circ} 01^{\prime} 11.68^{\prime \prime}$ & $47^{\circ} 37^{\prime} 29.81^{\prime \prime}$ & $427 \mathrm{~m}$ & Lowland meadow & C. meyeriana & Meadow soil & High grazing \\
\hline
\end{tabular}

damage other than the use pattern. Basic information on the plots and the climate data during the experimental period is provided in Tables 1, 2, respectively.

\section{Plant Measurements and Soil Sampling}

To eliminate the impact of marginal effects on the grassland plant communities, at the beginning of July in each year (usually approximately July 10 th), three main quadrats $(1 \times 1 \mathrm{~m})$ that were at least $10 \mathrm{~m}$ from the boundary of each plot and at least $30 \mathrm{~m}$ from each other were randomly selected in each sampling plot. Four additional quadrats were selected within 2-5 m of each main quadrat in the four cardinal directions. All plant species in each quadrat were recorded, and the height, number and absolute coverage of each species were measured. Then, the above-ground parts of the plants were clipped for the determination of aboveground biomass.

Soil samples were collected from two soil layers (0-20 and 21$40 \mathrm{~cm})$ in each quadrat. Five soil cores $(35-\mathrm{mm}$ diameter) were randomly collected in each quadrat, and the soil samples were air-dried before the analysis of their physicochemical properties.

\section{Calculation of Plant Community Characteristics and Determination of Soil Physicochemical Properties}

The mowed plants were dried in an oven at $105^{\circ} \mathrm{C}$ for $15 \mathrm{~min}$ and then dried at $65^{\circ} \mathrm{C}$ for $24-48 \mathrm{~h}$ to obtain the aboveground dry weight of the plants in each plot. Important values

TABLE 2 | Temperature and precipitation data during the test period.

\begin{tabular}{|c|c|c|c|c|}
\hline Item & 2015 & 2016 & 2017 & 2018 \\
\hline $\begin{array}{l}\text { Annual precipitation } \\
(\mathrm{mm})\end{array}$ & 696.60 & 560.90 & 319.40 & 584.10 \\
\hline $\begin{array}{l}\text { Annual average daily } \\
\text { temperature }\left({ }^{\circ} \mathrm{C}\right)\end{array}$ & 4.60 & 3.76 & 4.40 & 3.93 \\
\hline $\begin{array}{l}\text { Average daily } \\
\text { temperature from } \\
\text { January to July }\left({ }^{\circ} \mathrm{C}\right)\end{array}$ & 3.93 & 1.59 & 3.12 & 0.03 \\
\hline $\begin{array}{l}\text { Rainfall from January to } \\
\text { July (mm) }\end{array}$ & 301.40 & 275.10 & 96.40 & 127.10 \\
\hline $\begin{array}{l}\text { Average daily } \\
\text { temperature during the } \\
\text { growing season }\left({ }^{\circ} \mathrm{C}\right)\end{array}$ & 17.31 & 16.87 & 17.70 & 16.64 \\
\hline $\begin{array}{l}\text { Rainfall during the } \\
\text { growing season (mm) }\end{array}$ & 278.00 & 252.00 & 74.40 & 100.70 \\
\hline $\begin{array}{l}\text { Rainfall from November } \\
\text { of the previous year to } \\
\text { the next April (mm) }\end{array}$ & 35.90 & 34.40 & 43.80 & 41.00 \\
\hline
\end{tabular}

of C. meyeriana and other grasses (Zhao et al., 2013) were calculated, and plant diversity indices, including species richness, the Simpson, Shannon-Wiener, and Pielou indices (Smith and Wilson, 1996; Wang et al., 2019), and community stability (Liu et al., 2020) were calculated. The indices were calculated with the following formulas:

$$
\begin{gathered}
\text { Species richness index : } D s=\frac{S-1}{\ln N} \\
\text { Simpson index : } D=1-\left[\sum_{i=1}^{s}\left(P_{i}\right)^{2}\right] \\
\text { Shannon - Wiener index : } H=-\sum_{i=1}^{s}\left(P_{i} \ln P_{i}\right) \\
\text { Pielou index : } E=\frac{H}{\ln S}
\end{gathered}
$$

where $S$ is the total number of species occurring within the plot; $P_{i}=\frac{N_{i}}{N}, \mathrm{~N}$ is the total number of individuals in the site, and $\mathrm{Ni}$ is the number of species I.

The soil water content (SWC) of each soil sample was measured after drying at $105^{\circ} \mathrm{C}$ for $48 \mathrm{~h}$. The SBD was calculated as the mass of the oven-dried soil $\left(105^{\circ} \mathrm{C}\right)$ divided by the core volume. The soil $\mathrm{pH}$ was determined from a 1:2 (soil/water ratio) slurry of oven-dried soil and deionized water, which was measured with a $\mathrm{pH}$ meter after incubation at $25^{\circ} \mathrm{C}$ for $30 \mathrm{~min}$. The soil total nitrogen (STN) content was measured using the Kjeldahl method (Kalembasa and Jenkinson, 1973). STN concentration was measured using the Bremner (1965). Soil available nitrogen (AN), available potassium (AK), and available phosphorous (AP) contents were measured as described previously (Wu et al., 2011).

\section{Data Analysis}

All data are expressed as the mean \pm standard error (SE). Samples were subjected to ANOVA to distinguish significant differences by SAS software (version 9.2, SAS Institute, United States). The LSDs of the values were decided at the level of significance $(\alpha=0.05)$. Stepwise regression analysis was performed with SAS. Principal component analysis (PCA) was performed using R (version 3.6.3, packages: "FactoMineR" and "factoextra"). Structural equation modeling (SEM) was performed with Amos 24.0 (SPSS Statistics 24.0). 


\section{RESULTS}

\section{Effects of Utilization Mode on the Plant Community Characteristics and Soil Physicochemical Properties of Lowland Meadow}

Under the different utilization modes, above-ground plant biomass in the four grassland sites exhibited different trends. As shown in Figure 1, the biomass at the UN site decreased each year, the biomass at the MO and HG sites fluctuated, and the biomass at the MG site stabilized after 2016; its coefficient of variation was only $7.55 \%$.

Figure 2 shows that plant diversity similarly exhibited different patterns among the four sites. Among the sites, the UN site had the lowest plant diversity, which was significantly lower than that at the MO and HG sites $(p<0.05)$. Plant diversity at the UN site showed a decreasing, increasing, and then decreasing trend, and the plant diversity at the MG site exhibited a similar pattern. Starting in 2016, plant diversity was very similar between these two sites; among the indices, only species richness differed, being significantly higher at the MG site than at the UN site $(p<0.05)$. In addition, among the sites, the MO site exhibited the most stable plant diversity, which fluctuated greatly only in 2017. The variation coefficient of each of the four diversity indices did not exceed $10.11 \%$. Plant abundance at the HG site decreased each year, and the values of the other three diversity indices fluctuated greatly at this site, with the minimum coefficient of variation being $22.31 \%$.

To calculate community stability at the four sites, the distance from the stable point in each community was calculated via the distance formula (Supplementary Table 1), and stability exhibited the order UN (70.90) > MO (70.80) > HG (70.78) > MG (70.77).

Figure 3 shows that compared with $\mathrm{UN}, \mathrm{MO}$, and $\mathrm{HG}$ significantly increased $\mathrm{SBD}$ and soil $\mathrm{pH}$ while significantly reducing the SMC, SOM, STN, and alkali-hydrolysable nitrogen

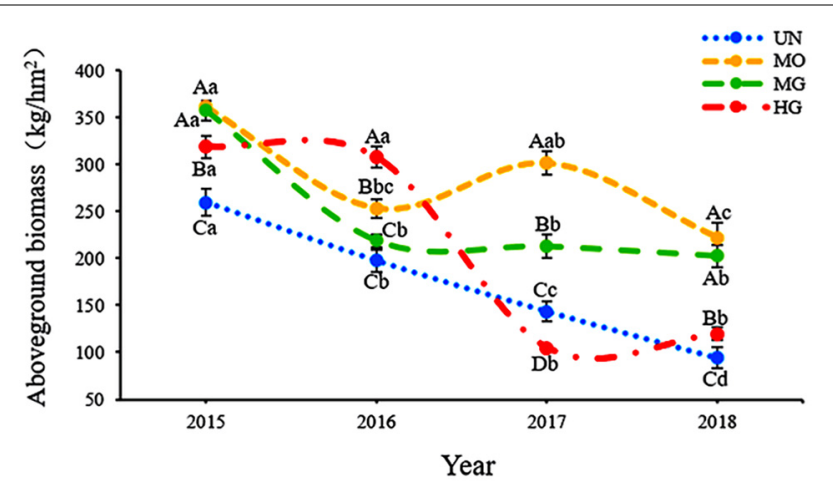

FIGURE 1 | Interannual variation in grassland plant biomass under different utilization patterns. Different capital letters indicate significant differences in plant biomass among sites in the same year at the 0.05 level, and different lowercase letters indicate significant differences in plant biomass between years within a site. contents. In addition, compared with UN, MG also significantly increased SBD and $\mathrm{pH}$, significantly reduced SOM contents at $0-20 \mathrm{~cm}$, and led to the convergence of the STN and alkalihydrolysable nitrogen contents in $0-40 \mathrm{~cm}$ soil. However, there was no uniform change trend for AP or AK. In addition, the SBD and the SOM and STN contents were very stable under all four utilization modes.

A PCA of the characteristics of the plant communities and the soil physicochemical properties was conducted. The properties of plants and soil were most similar between the MG and UN sites and most stable at the MO site. Among the modes, HG changed the plant community and soil physicochemical properties of the C. meyeriana lowland meadow most significantly (Figure 4).

\section{Analysis of Key Factors Affecting Plant Biomass Under Different Utilization Modes}

To clarify the key factors affecting the above-ground biomass of grassland plants under different utilization modes, stepwise regression analysis of the characteristics of grassland plant communities, soil physicochemical properties, and hydrothermal data from January to July and hydrothermal data from the growth period was performed. Table 3 shows that the key factors affecting the plant biomass of $C$. meyeriana meadow were consistent between the MG and HG sites and not significantly related to the hydrothermal conditions. However, the key factors that affected plant biomass significantly differed between the UN and MO sites because of the differing hydrothermal conditions. In all four sites, there was a significant positive correlation between plant biomass and the temperature from January to July.

To clarify the interactions among grazing intensity, hydrothermal conditions, soil physicochemical properties and plant biomass under grazing conditions, we performed SEM and obtained the structural equation model shown in Figure 5. Figure 5 shows that an increase in grazing intensity can be expected to increase the biomass of above-ground plants and decrease the SOM content in the $0-20 \mathrm{~cm}$ layer. In addition, the increase in temperature also contributed to the increase in plant biomass.

\section{DISCUSSION}

\section{Effects of Utilization Mode on Grassland Plant Communities}

Some scholars have demonstrated that external disturbances can affect the biomass of grassland plants (Kawada et al., 2008; Koyama et al., 2016). Our results showed that MO, MG, and HG all significantly increased plant biomass in the C. meyeriana lowland meadows (although HG reduced plant biomass in 2017, probably due to the little precipitation in that year). This result differs from that of Wang and Wesche (2016) and Lu et al. (2017). This difference is due to the simple community composition of the $C$. meyeriana meadow in its native state and the absolute dominance of $C$. meyeriana in the community. Even though the precipitation decreased in 2017 and the percentage of some 

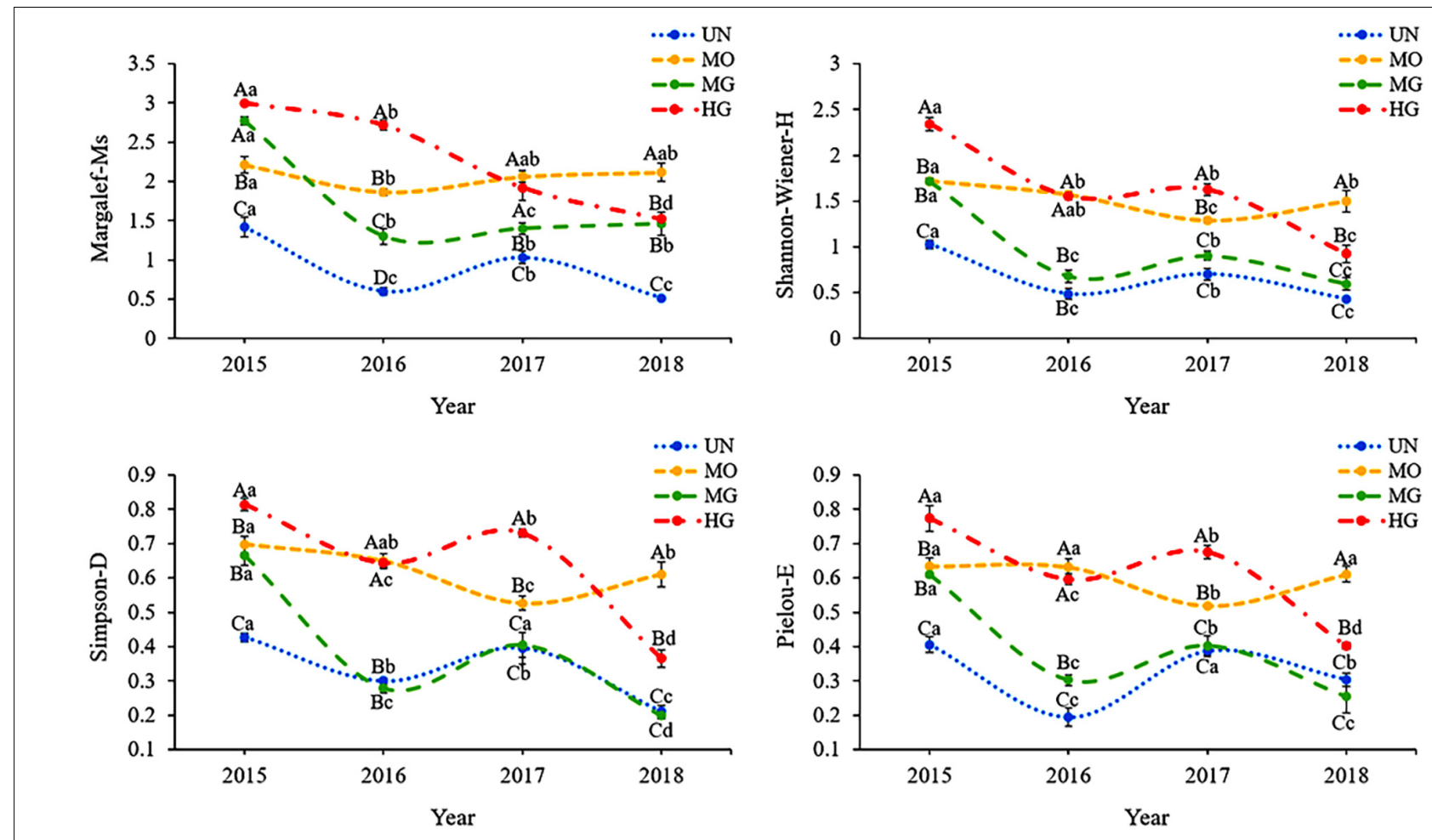

FIGURE 2 | Interannual variation in grassland plant diversity under different utilization patterns. Different capital letters indicate significant differences in a plant diversity index among sites in the same year at the 0.05 level, and different lowercase letters indicate significant differences in a plant diversity index between years within a site.

drought-loving plants increased, C. meyeriana still accounted for $50.09 \%$ of the community (Supplementary Table 1). However, compared to that of other types of grasses, the quality of C. meyeriana was lower. Therefore, after MO and MG, the proportion of miscellaneous grasses in C. meyeriana meadow increased, resulting in increases in plant biomass. Although HG increased plant biomass, meadow biomass decreased each year with increasing number grazing years under HG, especially in years with reduced precipitation. This increase under HG may reflect plant compensatory growth (McNaughton, 1979; Sun et al., 2019). In addition, the results indicated that the effect of grazing on grassland biomass is complex (Jinhua et al., 2010; Li et al., 2019).

In this study, the different utilization modes had different impacts on plant diversity. Among the sites, the MO site exhibited the least variation in the four diversity indices, and the interannual variation in the number of plant species was also minimal at this site. These findings indicate that MO helped maintain plant diversity in the lowland meadow. These results were obtained because mowing has relatively homogeneous effects on grasslands, prevents competing dominant species from eliminating competing vulnerable species, improves canopy radiation, ensures the growth of various plant species and thus maintains species diversity (Yang et al., 2012; Kose et al., 2019). Our results are also consistent with the research results of many studies (Verrier and Kirkpatrick, 2005; Socher et al., 2013; Smith et al., 2018). The mowing-associated factors that affect the diversity of grasses include mowing time, stubble height and mowing frequency (Malin et al., 2018; Chen et al., 2021). In addition, grassland type and climate conditions can affect experimental results (Su et al., 2017). For these reasons, the results of this experiment partially differed from the findings of Socher et al. (2012) and Lepš (2014). In the present experiment, the impacts of mowing and grazing on the diversity of $C$. meyeriana lowland meadows were the focus, and the impacts of specific mowing practices on plant diversity were not studied in depth. The results of this study show only that successive mowing maintained the stability of the $C$. meyeriana meadow plant community and do not reveal whether mowing once per year was the best management method or whether this mowing frequency was the optimal frequency for this management model.

In this study, the plant diversity indices at the HG site were all higher than those at the MG site, indicating that an increase in grazing intensity could lead to increases in the number of plant species and plant diversity in lowland meadows. The abundance of weeds at the HG site was higher than that at the MG site, which explained why plant diversity was higher at the HG site (Supplementary Table 2). This result is similar to the results of an experiment conducted by Zhang et al. (2017) in the Horqin Grassland, where the dominance of annual and other weeds increased under grazing conditions. In addition, the results of community stability calculations also indicated that the community composition at the MG site was more stable than that at the HG site (A lower score indicates a more stable 
A

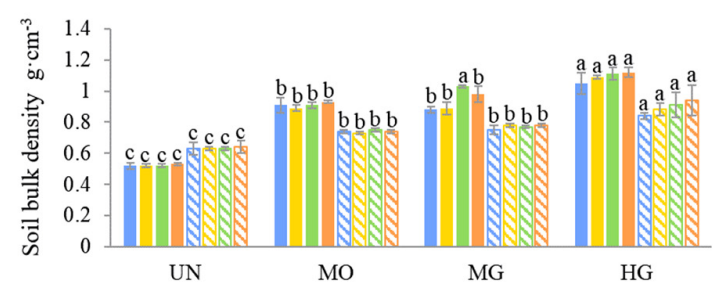

C

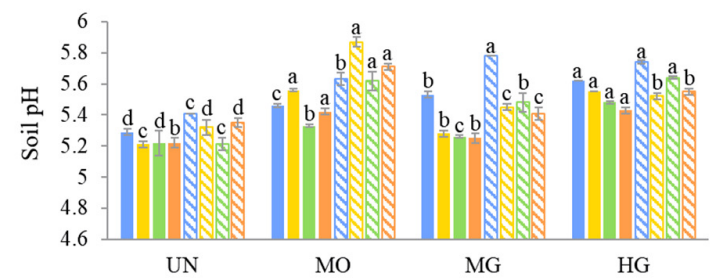

E$$
\text { 曻 }
$$

G

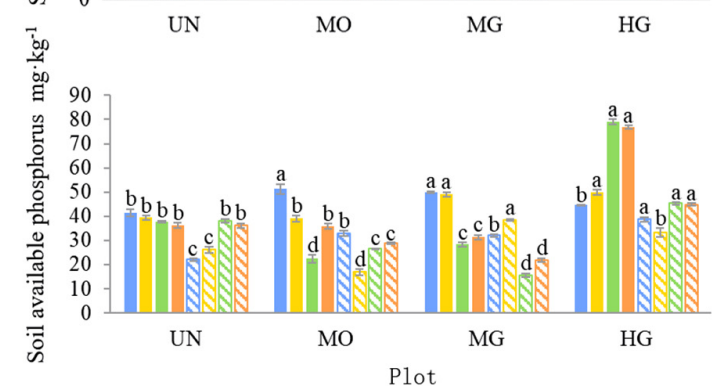

B



D

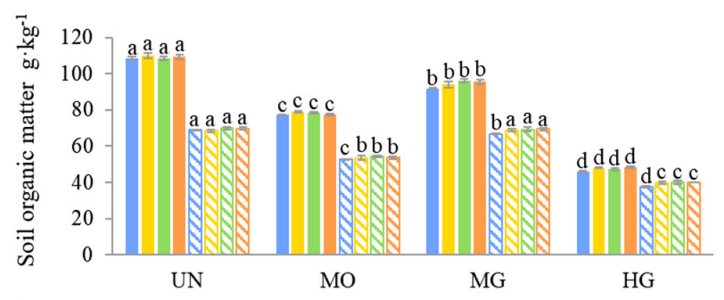

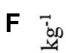

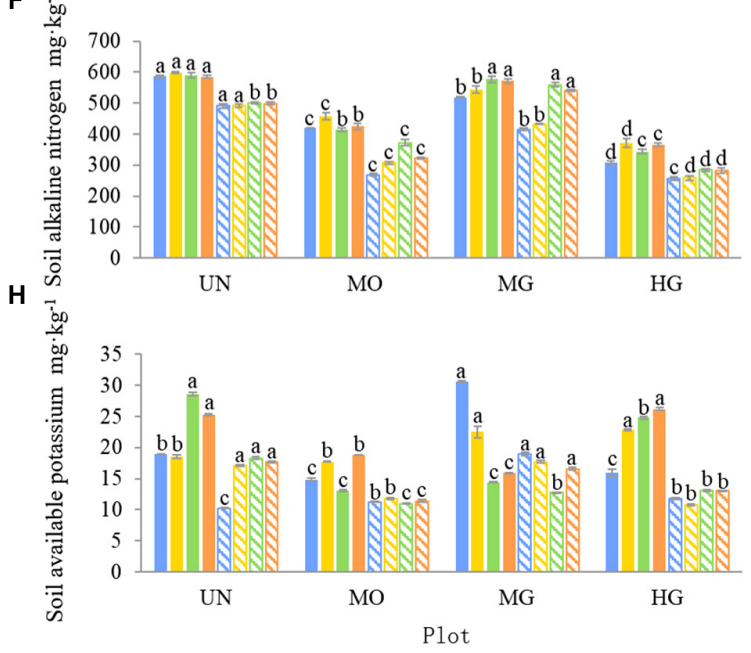

FIGURE 3 | Interannual variation in soil physicochemical properties under different utilization patterns. Different letters indicate significant differences in a physicochemical property of the same soil layer among sites within a year at the 0.05 level.

community; therefore, the MG plant community had the highest stability, Supplementary Table 1). In contrast, Spellmeier et al. (2019) in swamps of southwestern Brazil showed that grazing reduced plant species richness. Spellmeier et al. (2019) selected a test site with naturally high plant richness that was in its native state; the data showed that the species count at that site under non-degraded conditions was much higher than that in the C. meyeriana meadow considered in this study. In conclusion, our experimental results indicated that UN (enclosure) is not the most appropriate management method for meadows in the long run (Sun et al., 2020).

\section{Effects of Utilization Mode on Grassland Soil Physicochemical Properties}

As with plant diversity, the soil physicochemical properties were affected differently by the different utilization patterns. The results showed that compared with $\mathrm{UN}, \mathrm{MO}, \mathrm{MG}$, and $\mathrm{HG}$ all led to increases in SBD and $\mathrm{pH}$, although to different degrees, and that both properties tended to stabilize once the utilization mode remained unchanged for a long time. The reasons for the increases in $\mathrm{pH}$ may be the decrease in deadfall due to mowing or grazing, greater evaporation of soil water and increased salt accumulation, and the decomposition of livestock excrement, which increase soil pH (Gao et al., 2014; Hao and He, 2019; Cai et al., 2020). In contrast, SWC decreased to different degrees under the different utilization modes and was higher in the shallow soil layer than in the deep soil layer, especially at the MO and HG sites; this result may have been due to the increased compactness and decreased permeability of the soil, which would inhibit water entry into the deep soil layer (Ran et al., 2019). Furthermore, the different utilization modes led to different degrees of reduction in the SOM, STN and alkali-hydrolysable nitrogen contents. Mowing or grazing significantly reduces litter 


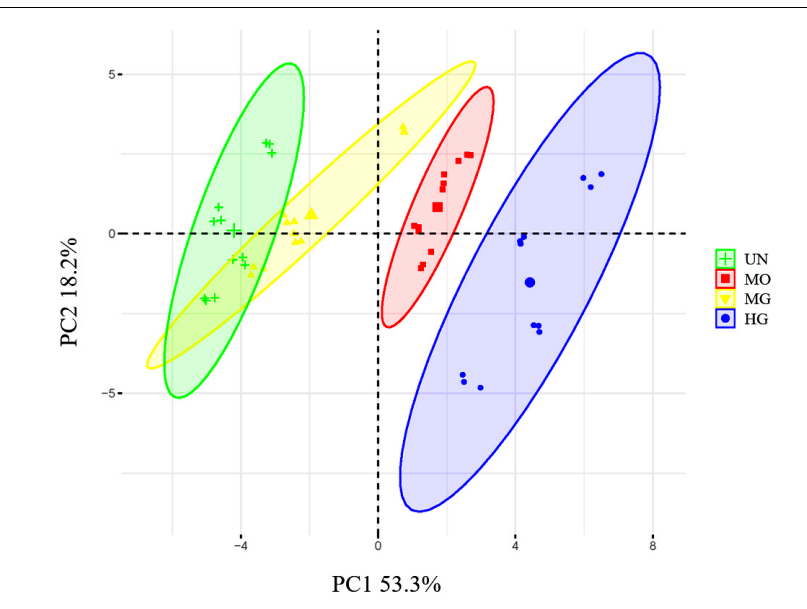

FIGURE 4 | Principal component analysis (PCA) of grassland plant community characteristics and soil physicochemical properties.

formation, thereby greatly reducing the possibility for external nutrient inputs into the soil; furthermore, some utilization modes can accelerate the consumption of soil nutrients by grassland plants and lead to a serious imbalance in soil nutrients (Wang et al., 2010). However, the effects on the soil AP and AK contents were not the same among the different utilization modes, which is consistent with the results of Lu et al. (2015). In summary, different utilization modes have different effects on soil chemical properties in different grassland types and at different utilization intensities.

Vegetation and soil are the most fundamental and important components of grassland ecosystems. Changes in soil and vegetation affect other properties of vegetation and soil and grassland ecosystems (Zuo et al., 2018). Furthermore, the various utilization modes differ in the type and intensity of influences they have on plants and soil (Sun et al., 2017; Guangyu et al., 2018; Wang et al., 2020b), for example, mowing directly and rapidly changes the structure and biomass of the plant community, but the changes in soil physical and chemical properties require some time to accumulate (Zong and Shi, 2020). In comparison to those of mowing, the impacts of HG on grassland plants and soil are more direct (Zhang et al., 2018a,b). In this study, MO did not strengthen the correlation between biomass and soil nutrient levels, whereas MG and HG strengthened the correlation between biomass and STN. Furthermore, the correlations between plant community diversity and soil physicochemical properties differed among the four sites (Supplementary Tables 3A,B). This finding is similar to the results of many studies in which the correlations between plant communities and soil physicochemical properties were not uniform across different grassland types and utilization patterns (Herrero-Jáuregui and Oesterheld, 2017; Fayiah et al., 2019; Gebregergs et al., 2019).

\section{Analysis of Factors Affecting Grassland Plant Biomass Under Grazing}

In recent years, extreme droughts and urban flooding events caused by global climate change have occurred frequently
(Zheng et al., 2012; Zhou et al., 2019). According to statistical records, until 2010, the average annual precipitation in the study area was $486.4 \mathrm{~mm}$, and the average annual temperature was $3.18^{\circ} \mathrm{C}$ (Tsolgor., 2015). During the experimental period, from 2015 to 2018, the annual rainfall in 2017 was much lower than $486.4 \mathrm{~mm}$, but the annual precipitation in the other 3 years was above the average (Table 2). Although they fluctuated greatly, the temperatures in each year were all above the historical average. The local hydrothermal changes in the study area represent a microcosm of global climate change; that is, temperature increases and extreme precipitation have become frequent. Therefore, to manage natural grasslands more scientifically, it would be helpful to study the influence of hydrothermal change on grassland ecosystems.

Existing studies have shown that climate change has significantly affected the above-ground productivity of terrestrial ecosystems. However, the magnitude and determinants of its effects vary among grassland ecosystems (Jiao et al., 2016; Li et al., 2018; Stan et al., 2020). Our results indicated that the plant biomass in the UN meadow decreased with the change in hydrothermal conditions from 2015 to 2018. In 2015, under the same hydrothermal conditions, the biomass at both the MO and MG sites was higher than that at the UN plot, indicating that moderate disturbance can increase the plant biomass of lowland meadows under adequate moisture conditions. Overall, the interannual variations in plant biomass from 2015 to 2018 were quite different among the sites under the four utilization modes. Biomass at the MO site showed changes that were consistent with the temperature trends. The results of both the Pearson correlation and stepwise regression analyses revealed a significant positive correlation between temperature and biomass at the MO site. The biomass at the MO site was higher than that at the other three sites in all 3 years except 2016, when it was lower than that at the HG site. These results indicate that MO helped to maintain the high biomass of the $C$. meyeriana meadow. This result is consistent with the results of Bernhardt-Römermann et al. (2011) and indicates that moderate mowing can help maintain high grassland productivity. Biomass at the MG site remained stable over the 3 years from 2016 to 2018 with no significant differences among years, and it was consistently higher than that at the UN site. These results indicate that moderate grazing helps maintain stable productivity in lowland meadows and are in line with the findings of Zhang et al. (2018c) and Nunes et al. (2019) that moderate grazing or reduced grazing intensity can maintain stable, high grassland productivity.

Biomass at the HG site decreased significantly after 2016 and was lower than that at the UN site in 2017, when the precipitation was much lower than the historical average. However, the structural equation model indicated that in this experiment, the increase in grazing intensity helped increase the biomass of the lowland meadow. The reasons for this contradiction may be that the soil moisture in the lowland meadow was higher under natural conditions than under grazed conditions and that grassland vegetation is typically 
TABLE 3 | Key factors determining plant biomass under different utilization modes.

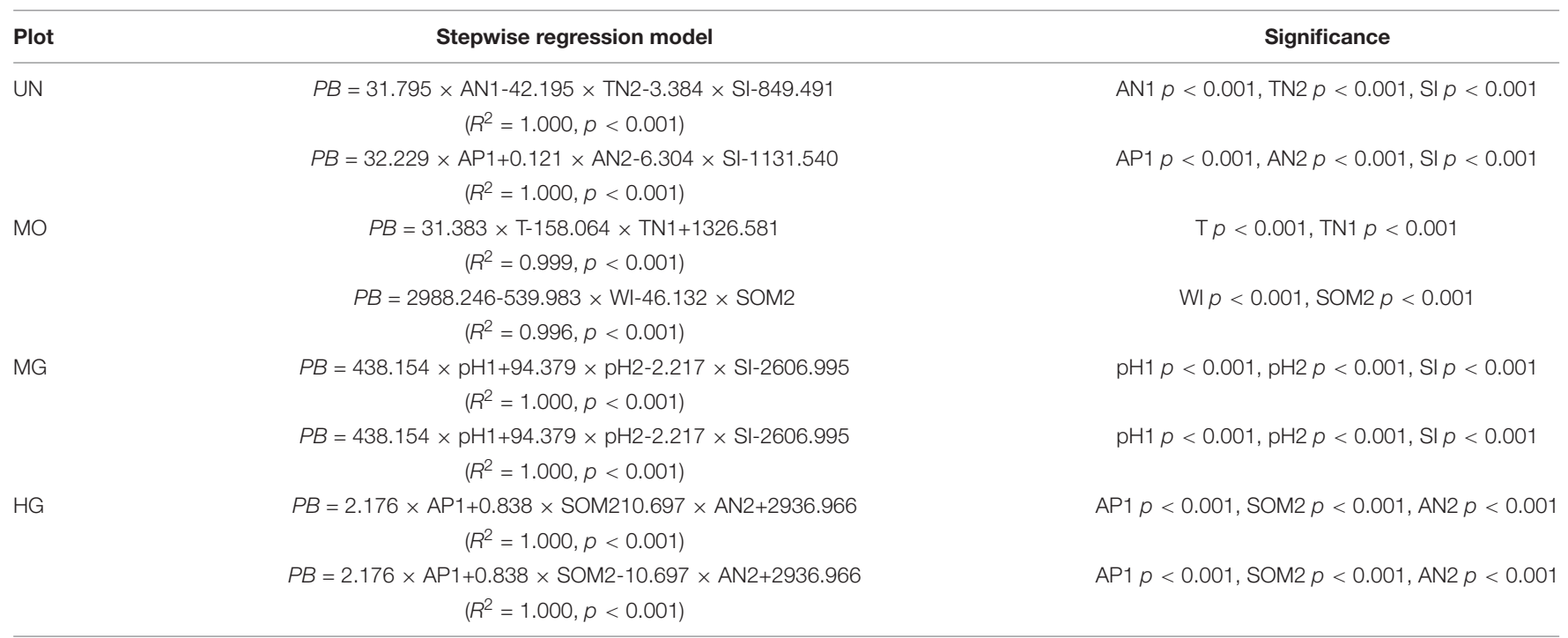

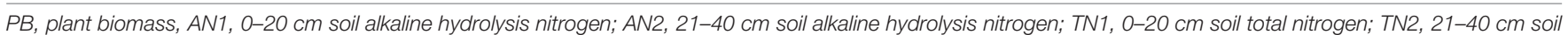

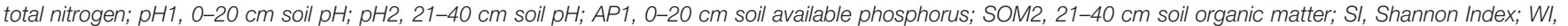

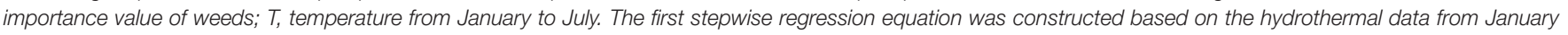
to July, and the second stepwise regression equation was based on the hydrothermal data during the plant growth period.

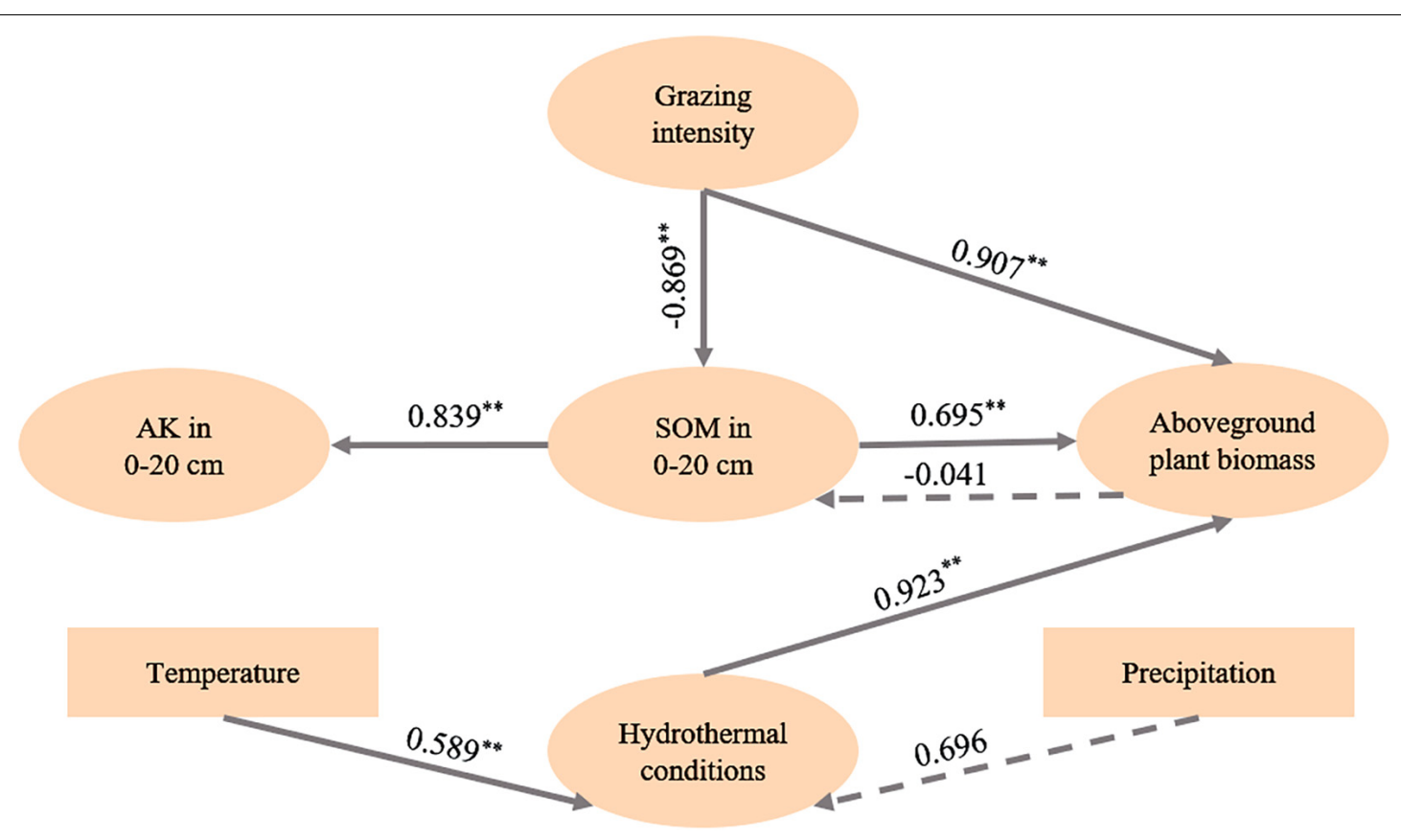

FIGURE 5 | Effects of grazing intensity and hydrothermal conditions on plant biomass and soil chemical properties. ${ }^{* \star}$ indicates $p<0.001$. Solid lines indicate that the correlation is significant; dotted lines indicate that the correlation is not significant. Hydrothermal conditions refer to the precipitation and average daily temperature from January to July. Structural equation model fitting indices: $\chi^{2} / \mathrm{df}=1.070, \mathrm{RMSEA}=0.086, \mathrm{CFI}=0.997, \mathrm{NFI}=1.000, \mathrm{NNFI}=0.985, \mathrm{SRMR}=0.083$.

water-loving and not drought-tolerant. The results in 2017 showed that it is a combination of factors such as climate and grazing that determine grassland plant biomass. In dry years, plants cannot grow normally, and precipitation becomes a stronger limiting factor than overgrazing for plant growth (Liu, 2019). Furthermore, Bai et al. (2012) suggested that heavy grazing accelerates the impacts of climate change on grassland ecosystems. However, Irisarri et al. (2016) found that the impacts of precipitation on semi-arid dwarf grasslands and mixed grasslands in North America were not affected by grazing; this divergent result may be related to the study differences in the site conditions of grasslands. 


\section{CONCLUSION}

Under global climate change in a Carex meyeriana lowland meadows, $\mathrm{MO}$ was identified as the most appropriate utilization mode for maintaining the overall stability of the plant community and the soil physicochemical properties, and MG was the best utilization mode for maintaining higher plant community stability and plant biomass. In addition, the MG site was the site most similar to the original grassland in its plant and soil physicochemical properties. Within a certain range, an increase in grazing intensity helped increase plant biomass in C. meyeriana lowland meadows. Under grazed conditions, an increase in temperature also increased plant biomass in C. meyeriana lowland meadow.

\section{DATA AVAILABILITY STATEMENT}

The original contributions presented in the study are included in the article/Supplementary Material, further inquiries can be directed to the corresponding author/s.

\section{REFERENCES}

Bai, Y., Wu, J., Clark, C. M., Pan, Q., Zhang, L., Chen, S., et al. (2012). Grazing alters ecosystem functioning and C:N:P stoichiometry of grasslands along a regional precipitation gradient. J. Appl. Ecol. 49, 1204-1215. doi: 10.1111/j.1365-2664. 2012.02205.x

Batista, P. H. D., de Almeida, G. L. P., de Lima, R. P., Pandorfi, H., da Silva, M. V., and Rolim, M. M. (2019). Impact of short-term grazing on physical properties of Planosols in Northeastern Brazil. Geoderma Region. 19:e00234. doi: 10.1016/j.geodrs.2019.e00234

Beck, J. J., Hernandez, D. L., Pasari, J. R., and Zavaleta, E. S. (2015). Grazing maintains native plant diversity and promotes community stability in an annual grassland. Ecol. Appl. 25, 1259-1270. doi: 10.1890/14-1093.1

Bernhardt-Römermann, M., Römermann, C., Sperlich, S., and Schmidt, W. (2011). Explaining grassland biomass - the contribution of climate, species and functional diversity depends on fertilization and mowing frequency. J. Appl. Ecol. 48, 1088-1097. doi: 10.1111/j.1365-2664.2011.01968.x

Bremner, J. M. (1965). Nitrogen Availability Indexes. Hoboken, NJ: John Wiley \& Sons, 1324-1345. doi: 10.2134/agronmonogr9.2.c37

Cai, Y., Yan, Y., Xu, D., Xu, X., and Eldridge, D. J. (2020). The fertile island effect collapses under extreme overgrazing: evidence from a shrub-encroached grassland. Plant Soil 448:12.

Chen, L., Baoyin, T., and Minggagud, H. (2021). Effects of mowing regimes on above- and belowground biota in semi-arid grassland of northern China. J. Environ. Manage 277, 111441. doi: 10.1016/j.jenvman.2020.111441

Chu, H., Zhang, C., Dong, Q., Shang, Z., Degen, A. A., Yang, X., et al. (2019). The effect of grazing intensity and season on the soil seed bank and its relation with above-ground vegetation on the alpine steppe. Agric. Ecosyst. Environ. 285:106622. doi: 10.1016/j.agee.2019.106622

Ciais, P., Sabine, C., Bala, G., Bopp, L., Brovkin, V., Canadel, J., et al. (2014). "Carbon and other biogeochemical cycles," in Climate Change 2013, eds O. Edenhofer, R. Pichs-Madruga, Y. Sokona, E. Farahani, S. Kadner, K. Seyboth, et al. (Cambridge: Cambridge University Press), 465-570.

Fayiah, M., Dong, S., Li, Y., Xu, Y., Gao, X., Li, S., et al. (2019). The relationships between plant diversity, plant cover, plant biomass and soil fertility vary with grassland type on Qinghai-Tibetan Plateau. Agric. Ecosyst. Environ. 286:106659. doi: 10.1016/j.agee.2019.106659

Fensham, R. J., Silcock, J. L., and Firn, J. (2014). Managed livestock grazing is compatible with the maintenance of plant diversity in semidesert grasslands. Ecol. Appl. 24, 503-517. doi: 10.1890/13-0492.1

\section{AUTHOR CONTRIBUTIONS}

GJ and BL were responsible for the data analysis and article writing. HY and GL assisted in the field test. YY was responsible for editing the manuscript. GC provided the experimental ideas, experimental guidance, and financial support. All authors contributed to the article and approved the submitted version.

\section{FUNDING}

This work was financially supported by the National Key Research and Development Project, Ministry of Science and Technology (2016YFC20500607).

\section{SUPPLEMENTARY MATERIAL}

The Supplementary Material for this article can be found online at: https://www.frontiersin.org/articles/10.3389/fpls.2021. 704511/full\#supplementary-material

Ganjurjav, H., Gao, Q., Gornish, E. S., Schwartz, M. W., Liang, Y., Cao, X., et al. (2016). Differential response of alpine steppe and alpine meadow to climate warming in the central Qinghai-Tibetan Plateau. Agric. Forest Meteorol. 223, 233-240. doi: 10.1016/j.agrformet.2016.03.017

Gao, A. M., Jing-Feng, W. U., Dai, F., Zhang, F. W., Han, Z. S., University, G. A., et al. (2014). Correlation study of soil compaction by mowing machine and alfalfa yield. Acta Prataculturae Sinica 23, 59-65.

Ge, Q., Dai, J., He, F., Zheng, J., Man, Z., and Zhao, Y. (2004). Spatiotemporal dynamics of reclamation and cultivation and its driving factors in parts of China during the last three centuries*. Progr. Nat. Sci. 14, 605-613. doi: 10.1080/ 10020070412331344021

Gebregergs, T., Tessema, Z. K., Solomon, N., and Birhane, E. (2019). Carbon sequestration and soil restoration potential of grazing lands under exclosure management in a semi-arid environment of northern Ethiopia. Ecol. Evol. 9, 6468-6479. doi: 10.1002/ece3.5223

Guangyu, Z., Zhuangsheng, T., Lei, C., Zhouping, S., and Lei, D. (2018). Overgrazing depresses soil carbon stock through changing plant diversity in temperate grassland of the Loess Plateau. Plant Soil Environ. 64, 1-6. doi: $10.17221 / 610 / 2017$-pse

Hao, Y., and He, Z. (2019). Effects of grazing patterns on grassland biomass and soil environments in China: a meta-analysis. PLoS One 14:e0215223. doi: 10.1371/ journal.pone.0215223

Harrison, S. (2020). Plant community diversity will decline more than increase under climatic warming. Philos. Trans. R. Soc. Lond. B Biol. Sci. 375:20190106. doi: $10.1098 /$ rstb.2019.0106

Herrero-Jáuregui, C., and Oesterheld, M. (2017). Effects of grazing intensity on plant richness and diversity: a meta-analysis. Oikos 127, 757-766. doi: 10.1111/ oik.04893

Hoffmann, C., Giese, M., Dickhoefer, U., Wan, H., Bai, Y., Steffens, M., et al. (2016). Effects of grazing and climate variability on grassland ecosystem functions in Inner Mongolia: synthesis of a 6-year grazing experiment. J. Arid Environ. 135, 50-63. doi: 10.1016/j.jaridenv.2016.08.003

Hu, G., Davies, J., Gao, Q., and Liang, C. (2018). Response of ecosystem functions to climate change and implications for sustainable development on the Inner Mongolian Plateau. Rangeland J. 40, 191-203. doi: 10.1071/rj18041

Irisarri, J. G., Derner, J. D., Porensky, L. M., Augustine, D. J., Reeves, J. L., and Mueller, K. E. (2016). Grazing intensity differentially regulates ANPP response to precipitation in North American semiarid grasslands. Ecol. Appl. 26, 1370-1380. doi: 10.1890/15-1332

Ji, L., Qin, Y., Jimoh, S. O., Hou, X., Zhang, N., Gan, Y., et al. (2020). Impacts of livestock grazing on vegetation characteristics and soil chemical properties of 
alpine meadows in the eastern Qinghai-Tibetan Plateau. Écoscience 27, 107-118. doi: 10.1080/11956860.2019.1710908

Jiao, C., Yu, G., He, N., Ma, A., Ge, J., and Hu, Z. (2016). Spatial pattern of grassland aboveground biomass and its environmental controls in the Eurasian steppe. J. Geogr. Sci. 27, 3-22. doi: 10.1007/s11442-017-1361-0

Jinhua, L., Zhenqing, L., and Jizhou, R. (2010). Effect of grazing intensity on clonal morphological plasticity and biomass allocation patternsof Artemisia frigidaandPotentilla acaulisin the Inner Mongolia steppe. New Zealand J. Agric. Res. 48, 57-61. doi: 10.1080/00288233.2005.9513631

Kalembasa, S. J., and Jenkinson, D. S. (1973). A comparative study of titrimetric and gravimetric methods for the determination of organic carbon in soil. J. Sci. Food Agric. 24, 1085-1090. doi: 10.1002/jsfa.2740240910

Kawada, K., Kurosu, M., Cheng, Y., Tsendeekhuu, T., Wuyunna, W., Nakamura, T., et al. (2008). Floristic composition, grazing effects and above-ground plant biomass in the Hulunbeier Grasslands of Inner Mongolia, China. J. Ecol. Environ. 31, 297-307. doi: 10.5141/jefb.2008.31.4.297

Kitchen, D. J., Blair, J. M., and Callaham, M. A. (2009). Annual fire and mowing alter biomass, depth distribution, and $\mathrm{C}$ and $\mathrm{N}$ content of roots and soil in tallgrass prairie. Plant Soil 323, 235-247. doi: 10.1007/s11104-009-9931-2

Kose, M., Liira, J., and Tali, K. (2019). Long-term effect of different management regimes on the survival and population structure of Gladiolus imbricatus in Estonian coastal meadows. Global Ecol. Conserv. 20:e00761. doi: 10.1016/j. gecco.2019.e00761

Koyama, A., Kubo, D., Yoshihara, Y., Jamsran, U., and Okuro, T. (2016). Response of degraded vegetation to introduction of prescribed burning or mowing management in a Mongolian steppe. Grassland Sci. 62, 37-44. doi: 10.1111/grs. 12113

Lepš, J. (2014). Scale- and time-dependent effects of fertilization, mowing and dominant removal on a grassland community during a 15-year experiment. J. Appl. Ecol. 51, 978-987.

Li, C., de Jong, R., Schmid, B., Wulf, H., and Schaepman, M. E. (2019). Spatial variation of human influences on grassland biomass on the Qinghai-Tibetan plateau. Sci. Total Environ. 665, 678-689. doi: 10.1016/j.scitotenv.2019.01.321

Li, W., Haiying, Y., Qiang Zhang, Y. X., Zexing, T., and Juha Alatalo, J. D. (2018). Responses of aboveground biomass of alpine grasslands to climate changes on the Qinghai-Tibet Plateau. J. Geograph. Sci. 28, 1953-1964.

Li, W., Li, X., Zhao, Y., Zheng, S., and Bai, Y. (2018b). Ecosystem structure, functioning and stability under climate change and grazing in grasslands: current status and future prospects. Curr. Opin. Environ. Sustainability 33, 124-135. doi: 10.1016/j.cosust.2018.05.008

Liu, J. (2019). Effects of Grazing and Precipitation on Plant Community Stability in Stipa Breviflora Desert Steppe. Doctor. thesis, Inner MongoliaAgricultural University, Hohhot.

Liu, J., Feng, C., Wang, D., Wang, L., Wilsey, B. J., Zhong, Z., et al. (2015). Impacts of grazing by different large herbivores in grassland depend on plant species diversity. J. Appl. Ecol. 52, 1053-1062. doi: 10.1111/1365-2664.12456

Liu, M., and Tian, H. (2010). China's land cover and land use change from 1700 to 2005: estimations from high-resolution satellite data and historical archives. Global Biogeochem. Cycles 24:3687. doi: 10.1029/2009gb003687

Liu, W., Fu, S., Yan, S., Ren, C., Wu, S., Deng, J., et al. (2020). Responses of plant community to the linkages in plant-soil C:N:P stoichiometry during secondary succession of abandoned farmlands. China. J. Arid Land 12, 215-226. doi: 10.1007/s40333-020-0009-6

Lu, X., Kelsey, K. C., Yan, Y., Sun, J., Wang, X., Cheng, G., et al. (2017). Effects of grazing on ecosystem structure and function of alpine grasslands in QinghaiTibetan Plateau: a synthesis. Ecosphere 8:e01656. doi: 10.1002/ecs2.1656

Lu, X., Yan, Y., Sun, J., Zhang, X., Chen, Y., Wang, X., et al. (2015). Short-term grazing exclusion has no impact on soil properties and nutrients of degraded alpine grassland in Tibet, China. Solid Earth 6, 1195-1205. doi: 10.5194/se-61195-2015

Luo, Y., Wang, C., Shen, Y., Sun, W., and Dong, K. (2019). The interactive effects of mowing and $\mathrm{N}$ addition did not weaken soil net $\mathrm{N}$ mineralization rates in semi-arid grassland of Northern China. Sci. Rep. 9:13457. doi: 10.1038/s41598019-49787-6

Malin, T., Balázs, D., Peter, P., Orsolya, V., Lars, W., and Per, M. (2018). Similar effects of different mowing frequencies on the conservation value of seminatural grasslands in Europe. Biodiversity Conserv. 27, 2451-2475. doi: 10.1007/ s10531-018-1562-6
McNaughton, S. J. (1979). Grazing as an optimization process: grass-ungulate relationships in the serengeti. Am. Nat. 113, 691-703. doi: 10.1086/283426

Nakahama, N., Uchida, K., Ushimaru, A., and Isagi, Y. (2016). Timing of mowing influences genetic diversity and reproductive success in endangered seminatural grassland plants. Agric. Ecosyst. Environ. 221, 20-27. doi: 10.1016/j.agee. 2016.01.029

Nakano, T., Bavuudorj, G., Iijima, Y., and Ito, T. Y. (2020). Quantitative evaluation of grazing effect on nomadically grazed grassland ecosystems by using timelapse cameras. Agric. Ecosyst. Environ. 287:106685. doi: 10.1016/j.agee.2019. 106685

Nunes, P.A.d.A, Bredemeier, C., Bremm, C., Caetano, L. A. M., de Almeida, G. M., de Souza Filho, W., et al. (2019). Grazing intensity determines pasture spatial heterogeneity and productivity in an integrated crop-livestock system. Grassland Sci. 65, 49-59. doi: 10.1111/grs.12209

Okach, D. O., Ondier, J. O., Kumar, A., Rambold, G., Tenhunen, J., Huwe, B., et al. (2018). Interactive influence of livestock grazing and manipulated rainfall on soil properties in a humid tropical savanna. J. Soils Sediments 19, 1088-1098. doi: 10.1007/s11368-018-2117-x

Polley, H. W., Derner, J. D., Jackson, R. B., Wilsey, B. J., and Fay, P. A. (2014). Impacts of climate change drivers on $\mathrm{C} 4$ grassland productivity: scaling driver effects through the plant community. J. Exp. Bot. 65, 3415-3424. doi: 10.1093/ jxb/eru009

Qin, J., Ren, H. Y., Han, G. D., Zhang, J., Browning, D., Willms, W., et al. (2019). Grazing reduces the temporal stability of temperate grasslands in northern China. Flora 259, 151450. doi: 10.1016/j.flora.2019.151450

Ran, X., Sheng-wei, Z., Zhong-yuan, Z., and Wen-tai, P. (2019). Effects of grazing on soil moisture and its response to rainfall in arid and semi-arid typical grassland. Chinese J. Grassland

Ren, H., Taube, F., Stein, C., Zhang, Y., Bai, Y., and Hu, S. (2018). Grazing weakens temporal stabilizing effects of diversity in the Eurasian steppe. Ecol Evol 8, 231-241. doi: 10.1002/ece3.3669

Rutherford, M. C., and Powrie, L. W. (2013). Impacts of heavy grazing on plant species richness: a comparison across rangeland biomes of South Africa. South African J. Bot. 87, 146-156. doi: 10.1016/j.sajb.2013.03.020

Salick, J., Fang, Z., and Hart, R. (2019). Rapid changes in eastern Himalayan alpine flora with climate change. Am. J. Bot. 106, 520-530. doi: 10.1002/ajb2.1263

Smith, A. L., Barrett, R. L., and Milner, R. N. C. (2018). Annual mowing maintains plant diversity in threatened temperate grasslands. Appl. Veget. Sci. 21, 207-218. doi: 10.1111 /avsc. 12365

Smith, B., and Wilson, J. B. (1996). A consumer's guide to evenness indices. Oikos 76:70. doi: $10.2307 / 3545749$

Socher, S. A., Prati, D., Boch, S., Müller, J., Baumbach, H., Gockel, S., et al. (2013). Interacting effects of fertilization, mowing and grazing on plant species diversity of 1500 grasslands in Germany differ between regions. Basic Appl. Ecol. 14, 126-136. doi: 10.1016/j.baae.2012.12.003

Socher, S. A., Prati, D., Boch, S., Müller, J., Klaus, V. H., Hölzel, N., et al. (2012). Direct and productivity-mediated indirect effects of fertilization, mowing and grazing on grassland species richness. J. Ecol. 100, 1391-1399. doi: 10.1111/j. 1365-2745.2012.02020.x

Spellmeier, J., Périco, E., Haetinger, C., Freitas, E. M., and Morás, A.P.d.B (2019). Effect of grazing on the plant community of a southern brazilian swamp. Floresta e Ambiente 26:33918. doi: 10.1590/2179-8087.033918

Stan, K., Sanchez-Azofeifa, A., Calvo-Rodriguez, S., Castro-Magnani, M., Chen, J., Ludwig, R., et al. (2020). Climate change scenarios and projected impacts for forest productivity in Guanacaste Province (Costa Rica): lessons for tropical forest regions. Reg. Environ. Change 20:14.

Su, R., Cheng, J., Chen, D., Bai, Y., and Li, J. (2017). Effects of grazing on spatiotemporal variations in community structure and ecosystem function on the grasslands of Inner Mongolia, China. Sci. Rep. 7:40.

Sun, J., Liu, M., Fu, B., Kemp, D., Zhao, W., Liu, G., et al. (2020). Reconsidering the efficiency of grazing exclusion using fences on the Tibetan Plateau. Sci. Bull. 65 , 1405-1414. doi: 10.1016/j.scib.2020.04.035

Sun, J., Ma, B., and Lu, X. (2017). Grazing enhances soil nutrient effects: trade-offs between above and below-ground biomass in alpine grasslands of the tibetan plateau. Land Degradation Dev. 29, 337-348. doi: 10.1002/ldr.2822

Sun, J., Zhan, T., Liu, M., Zhang, Z., Wang, Y., Liu, S., et al. (2019). Verification of the biomass transfer hypothesis under moderate grazing across the Tibetan 
plateau: a meta-analysis. Plant Soil 458, 139-150. doi: 10.1007/s11104-01904380-8

Swacha, G., Botta-Dukat, Z., Kacki, Z., Pruchniewicz, D., and Zolnierz, L. (2018). The effect of abandonment on vegetation composition and soil properties in Molinion meadows (SW Poland). PLoS One 13:e0197363. doi: 10.1371/journal. pone. 0197363

Teague, W. R., Dowhower, S. L., Baker, S. A., Haile, N., DeLaune, P. B., and Conover, D. M. (2011). Grazing management impacts on vegetation, soil biota and soil chemical, physical and hydrological properties in tall grass prairie. Agric. Ecosyst. Environ. 141, 310-322. doi: 10.1016/j.agee.2011.03.009

Tsolgor. (2015). Analysis on characteristics and trends of climate change in Zhalantun in the Past 50 Years. Inner Mongolia Sci. Technol. Econ. 3, 73-74.

Vermeire, L. T., Strong, D. J., Gates, E. A., Marlow, C. B., and Waterman, R. C. (2020). Can mowing substitute for fire in semiarid grassland? Rangeland Ecol. Manag. 73, 97-103. doi: 10.1016/j.rama.2019.08.006

Verrier, F. J., and Kirkpatrick, J. B. (2005). Frequent mowing is better than grazing for the conservation value of lowland tussock grasssland at Pontville. Tasmania. Austral Ecol. 30, 74-78. doi: 10.1111/j.1442-9993.2004.01425.x

Wang, C., Wei, M., Wu, B., Wang, S., and Jiang, K. (2019). Alpine grassland degradation reduced plant species diversity and stability of plant communities in the Northern Tibet Plateau. Acta Oecol. 98, 25-29. doi: 10.1016/j.actao.2019. 05.005

Wang, D., Chi, Z., Yue, B., Huang, X., Zhao, J., Song, H., et al. (2020a). Effects of mowing and nitrogen addition on the ecosystem $\mathrm{C}$ and $\mathrm{N}$ pools in a temperate steppe: a case study from northern China. Catena 185:104332. doi: 10.1016/j. catena.2019.104332

Wang, J., Zhao, M., Willms, W. D., Han, G., Wang, Z., and Bai, Y. (2011). Can plant litter affect net primary production of a typical steppe in Inner Mongolia? J. Veg. Sci. 22, 367-376. doi: 10.1111/j.1654-1103.2011.01257.x

Wang, L., Luan, L., Hou, F., and Siddique, K. H. M. (2020b). Nexus of grazing management with plant and soil properties in northern China grasslands. Sci. Data 7:39. doi: 10.1038/s41597-020-0375-0

Wang, X. T., Zhang, S. H., Chen, D. D., Tan, Y. R., Sun, D. S., and Guo-Zhen, D. U. (2010). The effects of natural grazing intensity on plant community and soil nutrients in alpine meadow. Acta Agrestia Sinica 18, 510-516.

Wang, Y., and Wesche, K. (2016). Vegetation and soil responses to livestock grazing in Central Asian grasslands: a review of Chinese literature. Biodiversity Conserv. 25, 2401-2420. doi: 10.1007/s10531-015-1034-1

Wei, L., Hai-Zhou, H., Zhi-Nan, Z., and Gao-Lin, W. (2011). Effects of grazing on the soil properties and $\mathrm{C}$ and $\mathrm{N}$ storage in relation to biomass allocation in an alpine meadow. J. Soil Sci. Plant Nutr. 11, 27-39. doi: 10.4067/s071895162011000400003

Wu, G.-L., Li, W., Zhao, L.-P., and Shi, Z.-H. (2011). Artificial management improves soil moisture, $\mathrm{C}, \mathrm{N}$ and $\mathrm{P}$ in an alpine sandy meadow of Western China. Pedosphere 21, 407-412. doi: 10.1016/s1002-0160(11)60142-2

$\mathrm{Xu}$, S., Jagadamma, S., and Rowntree, J. (2018). Response of grazing land soil health to management strategies: a summary review. Sustainability 10:4769. doi: $10.3390 /$ su10124769

Yang, H., Jiang, L., Li, L., Li, A., Wu, M., and Wan, S. (2012). Diversitydependent stability under mowing and nutrient addition: evidence from a 7-year grassland experiment. Ecol. Lett. 15, 619-626. doi: 10.1111/j.1461-0248.2012.01778.x

Yang, Z., Minggagud, H., Baoyin, T., and Li, F. Y. (2020). Plant production decreases whereas nutrients concentration increases in response to the decrease of mowing stubble height. J. Environ. Manage. 253, 109745. doi: 10.1016/j. jenvman.2019.109745

Zhan, T., Zhang, Z., Sun, J., Liu, M., Zhang, X., Peng, F., et al. (2020). Meta-analysis demonstrating that moderate grazing can improve the soil quality across China's grassland ecosystems. Appl. Soil Ecol. 147:103438. doi: 10.1016/j.apsoil.2019. 103438

Zhang, B., Beck, R., Pan, Q., Zhao, M., and Hao, X. (2019). Soil physical and chemical properties in response to long-term cattle grazing on sloped rough fescue grassland in the foothills of the Rocky Mountains, Alberta. Geoderma 346, 75-83. doi: 10.1016/j.geoderma.2019.03.029

Zhang, C., Dong, Q., Chu, H., Shi, J., Li, S., Wang, Y., et al. (2018a). Grassland community composition response to grazing intensity under different grazing regimes. Rangeland Ecol. Manage. 71, 196-204. doi: 10.1016/j.rama.2017.09. 007

Zhang, J., Zuo, X., Zhou, X., Lv, P., Lian, J., and Yue, X. (2017). Long-term grazing effects on vegetation characteristics and soil properties in a semiarid grassland, northern China. Environ. Monit. Assess. 189:216. doi: 10.1007/s10661-0175947-x

Zhang, M., Li, X. B., Wang, H., and Huang, Q. (2018b). Comprehensive analysis of grazing intensity impacts soil organic carbon: a case study in typical steppe of Inner Mongolia. China. Appl. Soil Ecol. 129, 1-12. doi: 10.1016/j.apsoil.2018.03. 008

Zhang, R. Y., Wang, Z. W., Han, G. D., Schellenberg, M. P., Wu, Q., and Gu, C. (2018c). Grazing induced changes in plant diversity is a critical factor controlling grassland productivity in the Desert Steppe, Northern China. Agric. Ecosyst. Environ. 265, 73-83. doi: 10.1016/j.agee.2018.05.014

Zhao, J., Liu, W., Ye, R., Lu, X., Zhou, Y., Yang, Y., et al. (2013). Responses of reproduction and important value of dominant plant species in different plant functional type in Kobresia meadow to temperature increase. Russian Journal of Ecology 44, 484-491. doi: 10.1134/s1067413613060131

Zheng, Z., Qi, S., and Xu, Y. (2012). Questionable frequent occurrence of urban flood hazards in modern cities of China. Nat. Hazards 65, 1009-1010. doi: 10.1007/s11069-012-0397-9

Zhou, S., Zhang, Y., Park Williams, A., and Gentine, P. (2019). Projected increases in intensity, frequency, and terrestrial carbon costs of compound drought and aridity events. Sci. Adv. 5:eaau5740. doi: 10.1126/sciadv.aau5740

Zong, N., and Shi, P. (2020). Clipping defoliation eliminates the stimulating effects of nitrogen enrichment on the aboveground productivity of an alpine meadow. Plant Soil Environ. 66, 47-56. doi: 10.17221/543/2019-pse

Zuo, X., Zhang, J., Lv, P., Wang, S., Yang, Y., Yue, X., et al. (2018). Effects of plant functional diversity induced by grazing and soil properties on aboveand belowground biomass in a semiarid grassland. Ecol. Indicators 93, 555-561. doi: 10.1016/j.ecolind.2018.05.032

Conflict of Interest: The authors declare that the research was conducted in the absence of any commercial or financial relationships that could be construed as a potential conflict of interest.

Copyright (C) $2021 \mathrm{Ji}, \mathrm{Li}$, Yin, Liu, Yuan and Cui. This is an open-access article distributed under the terms of the Creative Commons Attribution License (CC BY). The use, distribution or reproduction in other forums is permitted, provided the original author(s) and the copyright owner(s) are credited and that the original publication in this journal is cited, in accordance with accepted academic practice. No use, distribution or reproduction is permitted which does not comply with these terms. 